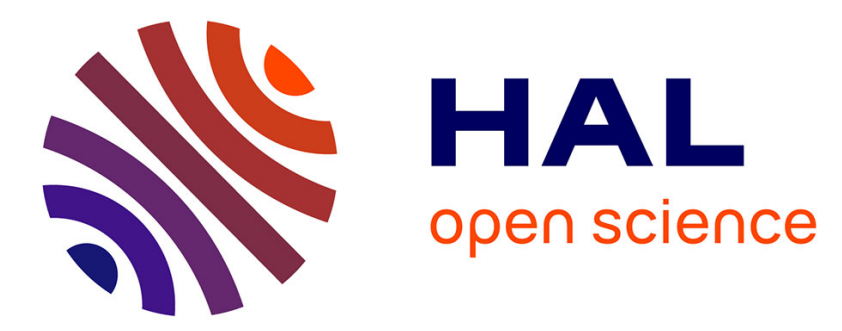

\title{
On the characteristic scales involved in a fragmentation process
}

C. Denoual, François Hild

\section{To cite this version:}

C. Denoual, François Hild. On the characteristic scales involved in a fragmentation process. Journal de Physique IV Proceedings, 1998, 2nd European Mechanics of Materials Conference on Mechanics of Materials with Intrinsic Length Scale: Physics, Experiments, Modelling and Applications, 08 (PR8), pp.Pr8-119-Pr8-126. 10.1051/jp4:1998815 . hal-02342763

\section{HAL Id: hal-02342763 \\ https://hal.science/hal-02342763}

Submitted on 4 Nov 2019

HAL is a multi-disciplinary open access archive for the deposit and dissemination of scientific research documents, whether they are published or not. The documents may come from teaching and research institutions in France or abroad, or from public or private research centers.
L'archive ouverte pluridisciplinaire HAL, est destinée au dépôt et à la diffusion de documents scientifiques de niveau recherche, publiés ou non, émanant des établissements d'enseignement et de recherche français ou étrangers, des laboratoires publics ou privés. 


\author{
EUROMECH - MECAMAT \\ $2^{\text {ND }}$ European Mechanics of Materials Conference \\ MAGDEBURG - GERMANY \\ 23-26 February, 1998
}

\title{
ON THE CHARACTERISTIC SCALES INVOLVED \\ IN A FRAGMENTATION PROCESS
}

C. DENOUAL ${ }^{1}$ and F. HLD ${ }^{2}$

${ }^{1}$ DGA / CTA - Département Surfaces et Matériaux en Conditions Sévères 16 bis, Avenue Prieur de la Cote d'Or, F-94114 Arcueil Cedex, France.

denoual@etca.fr

tel. (+33) 142319267

fax. $(+33) 142318966$

${ }^{2} \mathrm{LMT}-\mathrm{Cachan}$

E.N.S. de Cachan / C.N.R.S. / Université Paris 6

61, Avenue du Président Wilson, F-94235 Cachan Cedex, France.

hild@lmt.ens-cachan.fr

tel. (+33) 147402192

fax. (+33) 147402240 


\begin{abstract}
Dynamic loadings produce high stress waves leading to the fragmentation of brittle materials such as ceramics. The main mechanism used to explain the change of the number of fragments with stress rate is an obscuration (or shielding) phenomenon. A probabilistic damage model is proposed and scalings are proposed. This approach allows an estimation of the characteristic size of structure involved in the transition between single fragmentation (quasi-static loading) and multiple fragmentation (dynamic loading). This criterion is used to understand the mechanism leading to damage localization for low impact velocity.
\end{abstract}

\title{
1. INTRODUCTION
}

Bilayered armor with ceramic as front plate and steel as back plate has been used for several years to improve the efficiency of light or medium armor. The high hardness of ceramic materials favors projectile failure [1] and spreads the kinetic energy on a large surface of a ductile back face. The weight of the armor is reduced in comparison to an armor made of steel only. In most impact configurations, the stress field associated with impact can be assumed to be spherical and an analogy can be made between real impact failure morphologies and soft recovery experiments of divergent spherical stress load [2]. Stress waves produce damage both in compressive and tensile modes in two different locations in the ceramic (Fig. 1). Damage in compression is produced near the impact surface when shear stresses reach a threshold value which can be dependent on pressure and strain rate. In the bulk of the ceramic, damage in tension is observed as well. With a projectile velocity under $1000 \mathrm{~m} / \mathrm{s}$, no significant perforation can be observed while damage grows. One can then uncouple the damage evolution phase from the complete penetration phase. The complete perforation is dependent on the way the ceramic fractures in terms of damage location and evolution, and in terms of anisotropic behavior due to cracking.

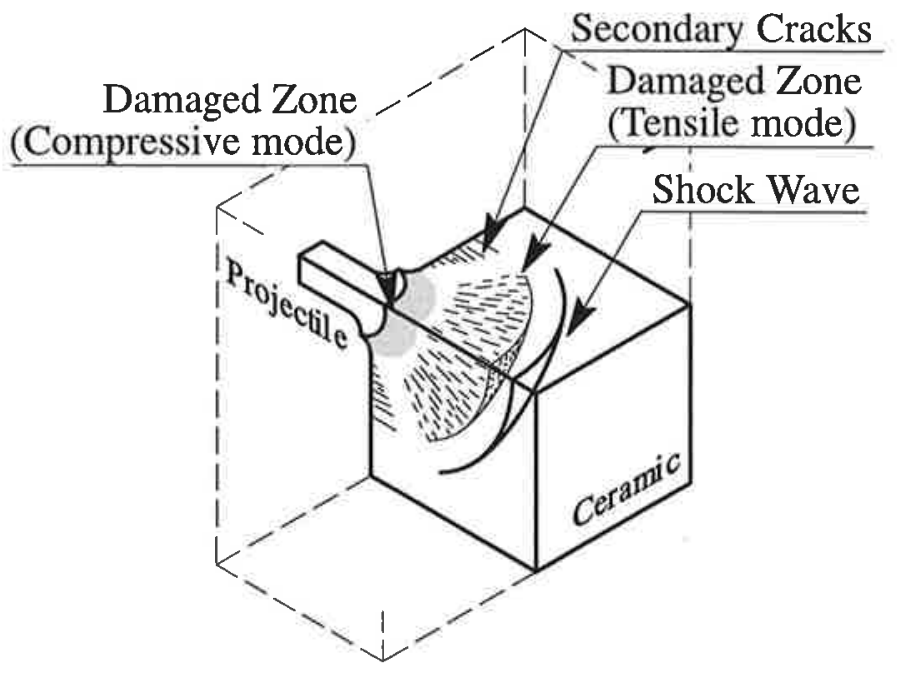

Figure 1: Morphology of damage in a ceramic specimen during impact.

Ceramic materials are known to break in a brittle way because of randomly distributed defects. This brittleness in tension is often related to the capability of supporting high loadings and breaking apart in a few 
micro-seconds. During the time of this relaxation, the stress wave is assumed to propagate only few times in the whole structure. When the stress state evolves significantly during this time, other defects can nucleate and modify the stress state of the structure: the ultimate strength can no longer be assumed to be the stress corresponding to the first defect failure.

Such dynamic loadings are obtained during impact of a steel blunt cylinder on the edge of a ceramic tile (Fig. 2). In the bulk of the impacted ceramic, damage in tension is observed when the hoop stress induced by the radial motion of the ceramic is sufficient to generate fracture in mode I. The stress velocity associated to this tensile stress state can be up to $5.10^{15} \mathrm{~Pa}_{\mathrm{s}}{ }^{-1}$. The modeling of the tensile degradation during impact can then be understood as an extension of the single failure mechanism, where not only one but several defects nucleate and lead to the failure of the structure.

In this study, a damage evolution law is based upon the modeling of the nucleation of many flaws. The main mechanism used to explain the change of the number of activated flaws with stress rate is an obscuration (or shielding) phenomenon. After a presentation of a probabilistic approach, a damage model is derived. The transition between single and multiple fragmentation is then discussed in terms of characteristic scales.
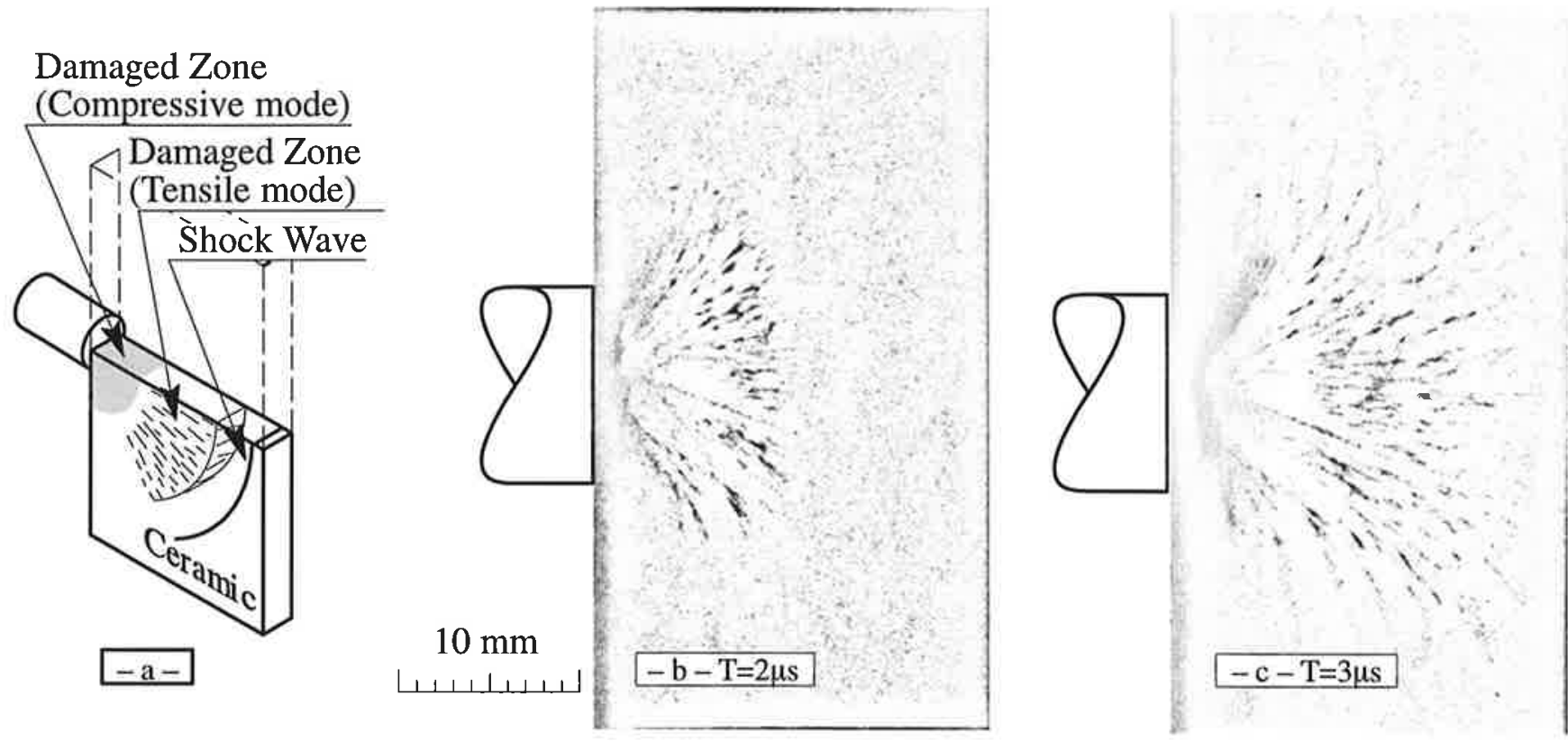

Figure 2: a) Edge-on impact configuration, b) and c) flaws nucleation during impact on a SiC ceramic (SSiC) with a projectile velocity of $203 \mathrm{~m} / \mathrm{s}$.

\section{PROBABILISTIC APPROACH}

\subsection{Single Fragmentation}

The failure of a ceramic in quasi-static tension is due to defects $d_{\mathrm{i}}$ of random location $x$ defined by a failure stress $\sigma_{\mathrm{i}}(x)$. When an equivalent stress $\sigma(\mathrm{x})$, e.g. maximum principal stress, is greater than $\sigma_{\mathrm{i}}(x)$, a crack emanating from the defect leads to the failure of the whole structure. It is worth mentioning that a failure is not necessarily due to the largest defect but to the "weakest link", i.e. the first location where $\sigma_{i}(x) \leq \sigma(x)$. Therefore, the ultimate strength of a ceramic specimen is not deterministic and a failure probability $P_{f}$ must be defined and can be described by a Weibull law [3]

$$
\begin{gathered}
P_{f}=1-\exp \left[-\lambda(\sigma) V_{\mathrm{eff}}\right] \\
\lambda(\sigma)=\lambda_{o}\left(\frac{\sigma}{\sigma_{o}}\right)^{m}
\end{gathered}
$$

where $\lambda$ is the defect density, $\sigma_{o}$ a scale parameter relative to a reference density $\lambda_{o}, m$ the Weibull modulus and $V_{\text {eff }}$ the effective volume [4]. Equation (1) allows to express the mean failure stress $\sigma_{\mathrm{w}}$ and the standard 
deviation $\sigma_{\text {sdev }}$ in a closed-form

$$
\sigma_{\mathrm{w}}=\sigma_{o}\left(V_{\text {eff }} \lambda_{o}\right)^{-\frac{1}{m}} \Gamma\left(\frac{m+1}{m}\right) ; \sigma_{\text {sdev }}^{2}=\sigma_{o}^{2}\left(V_{\text {eff }} \lambda_{o}\right)^{-\frac{2}{m}} \Gamma\left(\frac{m+2}{m}\right)-\sigma_{\mathrm{w}}^{2}
$$

where $\Gamma$ is the Euler function of the second kind.

\subsection{Multiple Fragmentation}

In the bulk of an impacted ceramic, multiple fragmentation is observed (Figs. $2 b$ and $2 c$ ). Each event corresponds to a mode I crack initiating on micro-defects. When such a fracture is initiated, the volume affected by fracture is a complex function of time, crack velocity and stress wave celerity. In order to simplify the following development, the shape of the affected (or interaction) volume $V_{\mathrm{i}}$ is supposed to be constant, i.e. all the interaction volumes are self-similar and $V_{\mathrm{i}}$ can be written as

$$
V_{\mathrm{i}}(T-t)=S[\alpha C(T-t)]^{3}
$$

where $\alpha C$ is the velocity of a propagating crack, $S$ a shape parameter, $C$ a longitudinal stress wave velocity so that $\alpha C(T-t)$ is a representative length of the relaxation volume at the current time $T$ around a broken flaw at time $t<T$. The shape parameter $S$ is chosen in order to have $\mathrm{d} \sigma / \mathrm{d} t \leq 0$ in $V_{\mathrm{i}}$, i.e. no new nucleations can occur in $V_{\mathrm{i}}$.

To understand why a crack nucleates, one has to model the interaction of a nucleated defect and other defects that would nucleate. With a constant direction of the maximum principal stress and a small stress gradient, the space dimension can be uncoupled from the tensile stress (or time) dimension and the flaw nucleation can be represented on a space-time graph (Fig. 3). The space location of a defect is represented in a simple abscissa of an $x-y$ graph where the $y$-axis represents its time (or stress) to failure. In this graph, a shaded cone represents the expansion of the interaction volume with time due to nucleation and propagation of a crack. The defects outside the shaded cones can nucleate and produce their own increasing interaction volume (e.g. defects No. 1 and No. 2 of Fig. 3). Inside the cones, the defects that should have broken do not nucleate (e.g. defects No. 3 and No. 4) since they are obscured.

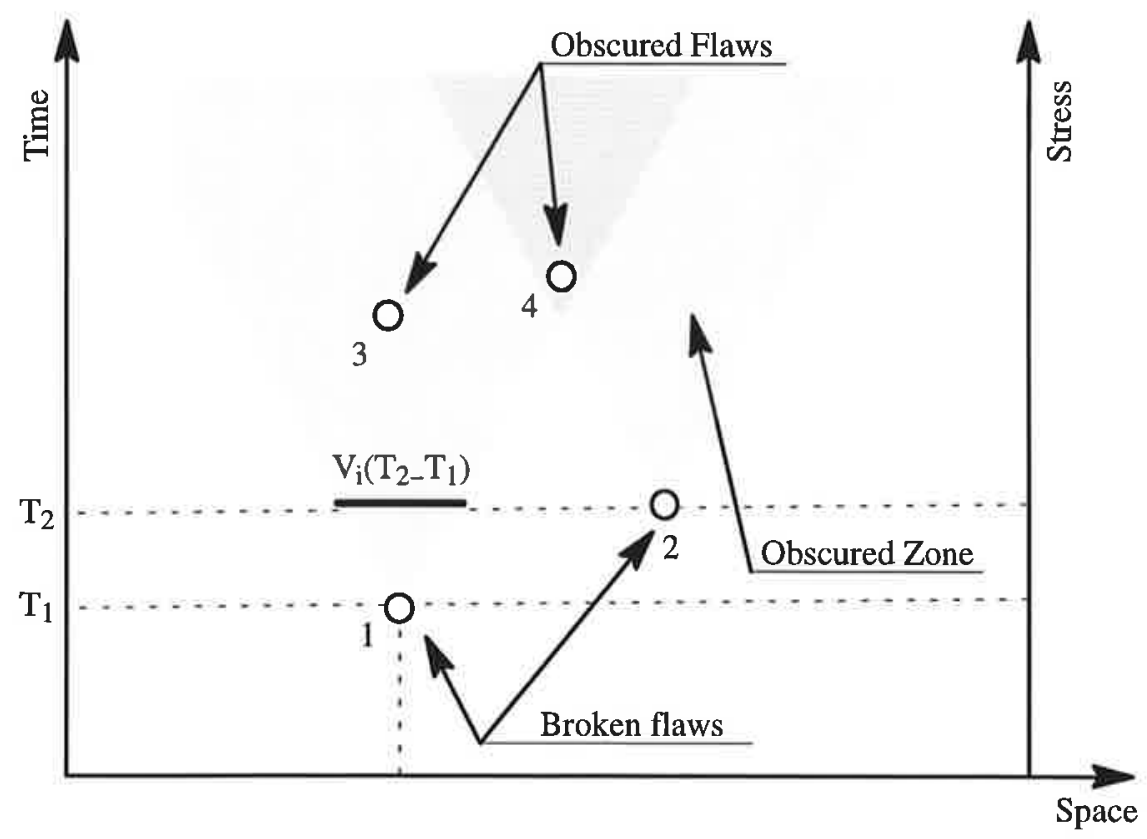

Figure 3: The obscuration phenomena.

Only defects in the non-obscured volumes can nucleate and produce a crack. The density of effectively nucleated defects $\lambda_{\mathrm{b}}$ can therefore be calculated in a incremental way

$$
\frac{\mathrm{d} \lambda_{\mathrm{b}}}{\mathrm{d} t}(T)=\frac{\mathrm{d} \lambda}{\mathrm{d} t}(T)\left(1-P_{\mathrm{o}}(T)\right) \text { with } \quad \lambda_{\mathrm{b}}(T=0)=0
$$


with $\lambda$ a function of $\sigma(T)$ (see Eqn. (2)) and $P_{\mathrm{o}}$ the obscuration probability (at least one defect exists in the horizon) expressed as [6], [7]

$$
P_{\mathrm{o}}=1-\exp [-\mathcal{H}(T) \lambda(T)]
$$

where $\mathcal{H}(T)$ is the mean volume of the space-time cones [8] defined by

$$
\mathcal{M}(T) \lambda(T)=\int_{0}^{T} \frac{\mathrm{d} \lambda}{\mathrm{d} t}(t) V_{\mathrm{i}}(T-t) \mathrm{d} t .
$$

Equation (6) can be compared to Eqn. (1) if one remembers that, for low stress rates, the obscured volume is limited by the volume of the structure. The proposed model therefore corresponds to a weakest-link approach when only one defect obscures the whole structure.

\subsection{Damage Model}

One can notice that $P_{\mathrm{o}}$ is also the fraction of relaxed zones and can therefore be related to a damage variable $D$ by the relation $P_{0}=D$. The proposed damage variable is defined with the assumption that many cracks nucleate and propagate due to a tensile stress expressed in the direction of the maximum principal stress. Since the cracks will be strongly oriented, an anisotropic damage description is chosen [9].

This anisotropic description is expressed through a second order damage tensor. The damage tensor $D_{i j}$ is diagonal in the eigen directions of stress tensor $\underline{\sigma}$ so that only 3 variables $\left(D_{1}, D_{2}, D_{3}\right)$ have to be computed. The relationship between the microscopic principal stress $\sigma_{i}$ and the macroscopic one $\left(\Sigma_{i}\right)$ is

$$
\Sigma_{i}=\left(1-D_{i}\right) \sigma_{i} \text { with } i=1,3
$$

The compliance tensor $\underline{\underline{S}}$, written by using the assumption that the principal damage frame and the stress eigen directions are identical, is equal to

$$
\underline{S}=\frac{1}{E}\left[\begin{array}{ccc}
\frac{1}{1-D_{1}} & -v & -v \\
-v & \frac{1}{1-D_{2}} & -v \\
-v & -v & \frac{1}{1-D_{3}}
\end{array}\right]
$$

where $E$ is the Young's modulus and $v$ the Poisson's ratio. This approach is useful when multiple crack patterns are superimposed. The evolution of $D_{i}$ is expressed in a differential form in order to be implemented in the Finite Element code PamShock [10] by using Eqns. (2), (5), (6) and (7)

$$
\frac{\mathrm{d}^{2}}{\mathrm{~d} t^{2}}\left(\frac{1}{1-D_{i}} \frac{\mathrm{d} D_{i}}{\mathrm{~d} t}\right)=3 ! \lambda_{o}\left(\frac{\sigma_{i}}{\sigma_{o}}\right)^{m} S(\alpha C)^{3}
$$

It is worth noting that $D_{i}$ approaches smoothly 1 and does not need any cut-off. According to classical results of Continuum Damage Mechanics, the evolution of $D_{i}$ is stopped if $\mathrm{d} \sigma / \mathrm{d} t \leq 0$. The eigen directions $\left(\underline{d}_{1}\right.$, $\underline{d}_{2}, \underline{d}_{3}$ ) associated to $D_{1}, D_{2}, D_{3}$ may change at each time step until $D_{1}$ reaches a threshold value $D_{\text {th }}=0.01$. Only the direction $\underline{d}_{1}$ is then locked, the other directions follow the eigen directions of $\underline{\underline{\sigma}}$, with the constraint to be perpendicular to $\underline{d}_{1}$. When $D_{2}$ reaches the threshold value, the whole directions are locked.

\subsection{Scaling}

To analyze the change of behavior with respect to the stress velocity, it is convenient to describe the damage evolution in a dimensionless manner so that only a reduced set of relevant material characteristics is used. In the case of a constant stress rate $\mathrm{d} \sigma / \mathrm{d} t=\dot{\sigma}$, a dimensionless flaw density $\left(\bar{\lambda}=\lambda / \lambda_{\mathrm{c}}\right)$, time $\left(\overline{\mathrm{T}}=\mathrm{T} / \mathrm{t}_{\mathrm{c}}\right)$, volume $\left(\overline{\mathrm{V}}=\mathrm{V} / \mathrm{V}_{\mathrm{c}}\right)$ are defined by the following condition

$$
\lambda_{c} V_{c}=1 \text { with } \lambda_{c}=\lambda\left(t_{c}\right) \text { and } V_{c}=V_{i}\left(t_{c}\right)
$$

where the subscript ' $c$ ' denotes characteristic quantities. The characteristic time is thus the time for which 
one defect is able to break in the characteristic volume. Equation (11) leads to the following expression for the characteristic time and volume

$$
t_{c}=\left[\lambda_{o}\left(\frac{\dot{\sigma}}{\sigma_{o}}\right)^{m} S(\alpha C)^{3}\right]^{-\frac{1}{m+3}} \quad ; \quad V_{c}=\left[\lambda_{o}\left(\frac{\dot{\sigma}}{\sigma_{o}}\right)^{m}\left(S^{1 / 3} a C\right)^{-m}\right]^{\frac{-3}{m+3}}
$$

Lastly, a dimensionless stress is defined by

$$
\bar{\sigma}=\frac{\sigma}{\sigma_{\mathrm{c}}} \quad \text { with } \quad \sigma_{\mathrm{c}}=\dot{\sigma} t_{\mathrm{c}}
$$

The set of material parameters is then reduced to the Weibull modulus only. The damage evolution due to a constant stress rate is expressed as a function of the corresponding dimensionless stress $\bar{\sigma}$ by using Eqns. (2), (6) and (7)

$$
D=1-\exp \left[-\frac{3 ! m !}{(m+3) !} \bar{\sigma}^{m+3}\right]
$$

It is interesting to notice that for $m \geq 3, D(\bar{\sigma}=1) \approx 0$ and $D(\bar{\sigma}=2) \approx 1$ so that the evolution of damage occurs when the stress evolves from $\sigma_{c}$ to $2 \sigma_{c}$. The ultimate macroscopic stress $(\mathrm{d} \Sigma / \mathrm{d} \sigma=0) \Sigma_{\mathrm{u}}$ is calculated by using Eqns.(2), (6), (7), (8) and is proportional to $\sigma_{c}$

$$
\Sigma_{u}=\sigma_{c}\left[\frac{1}{6 e} \frac{(m+2) !}{m !}\right]^{\frac{1}{m+3}}
$$

\subsection{Validations}

The probabilistic approach has been validated by using an Edge on Impact configuration with two different silicon carbides (Fig. 4). These materials are made by Céramiques et Composites, France (SSiC), and CERCOM, USA (SiC-B) and have their properties listed in Table 1. The two materials are comparable with the exception of the mean strength and the Weibull modulus.

Table 1. Material properties of two SiC ceramics.

\begin{tabular}{lcc}
\hline Property & SSiC & SiC-B \\
\hline Young's Modulus & $410 \mathrm{GPa}$ & $450 \mathrm{GPa}$ \\
Density & 3.15 & 3.18 \\
Weibull Modulus & 9.3 & 18 \\
Mean Strength & $350 \mathrm{MPa}$ & $553 \mathrm{MPa}$ \\
Effective Volume & $1.25 \mathrm{~mm}^{3}$ & $1.25 \mathrm{~mm}^{3}$ \\
\hline
\end{tabular}

During impact, the damage zone evolves in a different way with respect to the projectile velocity. With an impact of high velocity, the damage is homogeneous in a circular zone in front of the projectile. Below a critical velocity depending on the material, the damage is localized in thinner and thinner corridors when the velocity decreases (Fig. 4). This localization of the damaged zone leads to a fragmentation process where the fragment sizes increase when the impact energy decreases. This leads to the common hypothesis that the corridors are due to the transition between dynamic loadings where no localization occurs and quasi-static loadings for which the tile is broken in few pieces. In the following section, a criterion is proposed for damage localization by examining the validity domain of both single fragmentation (i.e. weakest link hypothesis) and multiple fragmentation based upon the probabilistic approach described herein.

\section{SINGLE/MULTIPLE FRAGMENTATION}

\subsection{Scale effects}

Figure 5 shows the evolution of the ultimate stress vs. stress rate for single fragmentation and multiple fragmentation in a volume in tension $V$ equal to $V_{\text {eff. }}$ The lines represent analytical solutions while the dots and 

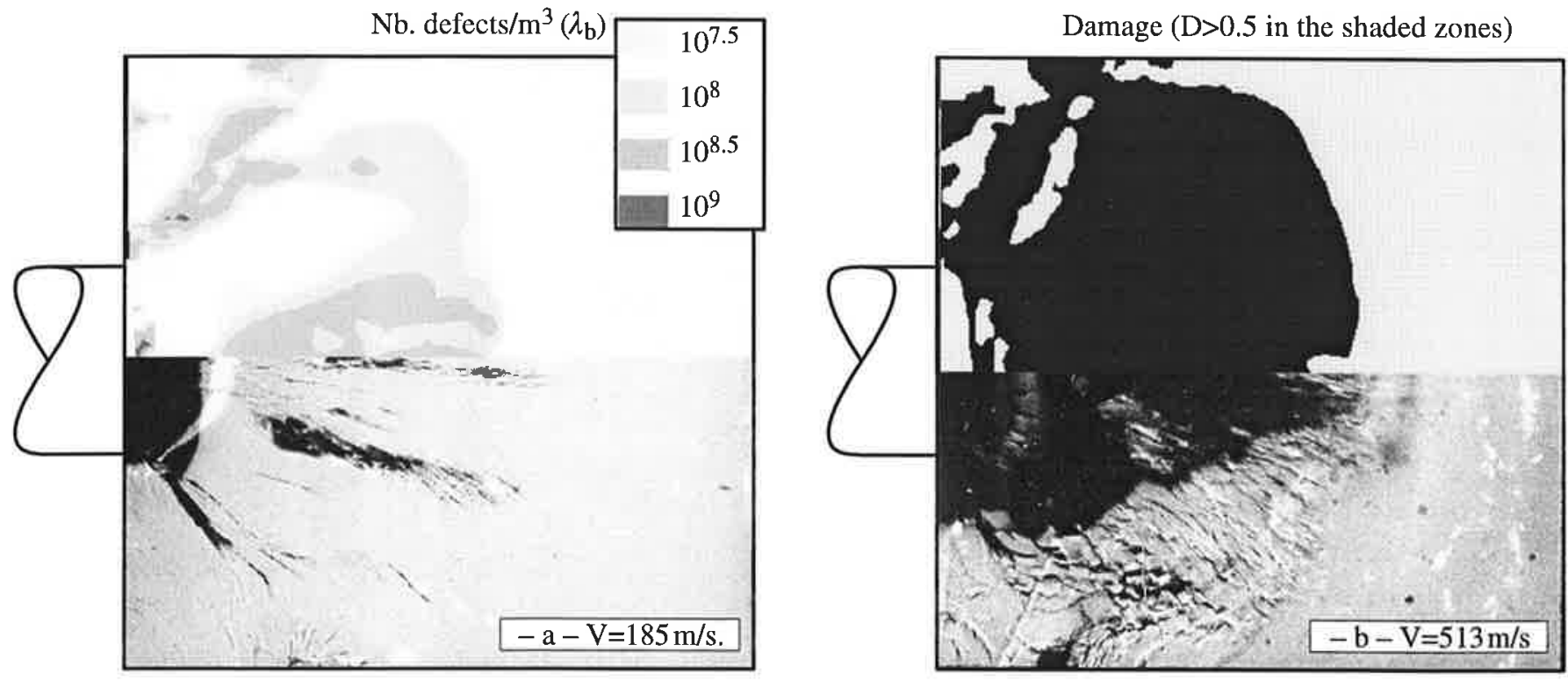

Figure 4: Edge-on impacts on SiC CERCOM tiles (simulated-top, observed-bottom), $\mathrm{a}-\mathrm{V}=185 \mathrm{~m} / \mathrm{s}$ (the damage is localized in thin corridors), $\mathrm{b}-\mathrm{V}=513 \mathrm{~m} / \mathrm{s}$ (the damage is not localized). Pictures were provided by E. Straßburger and H. Senf, EMI [5].

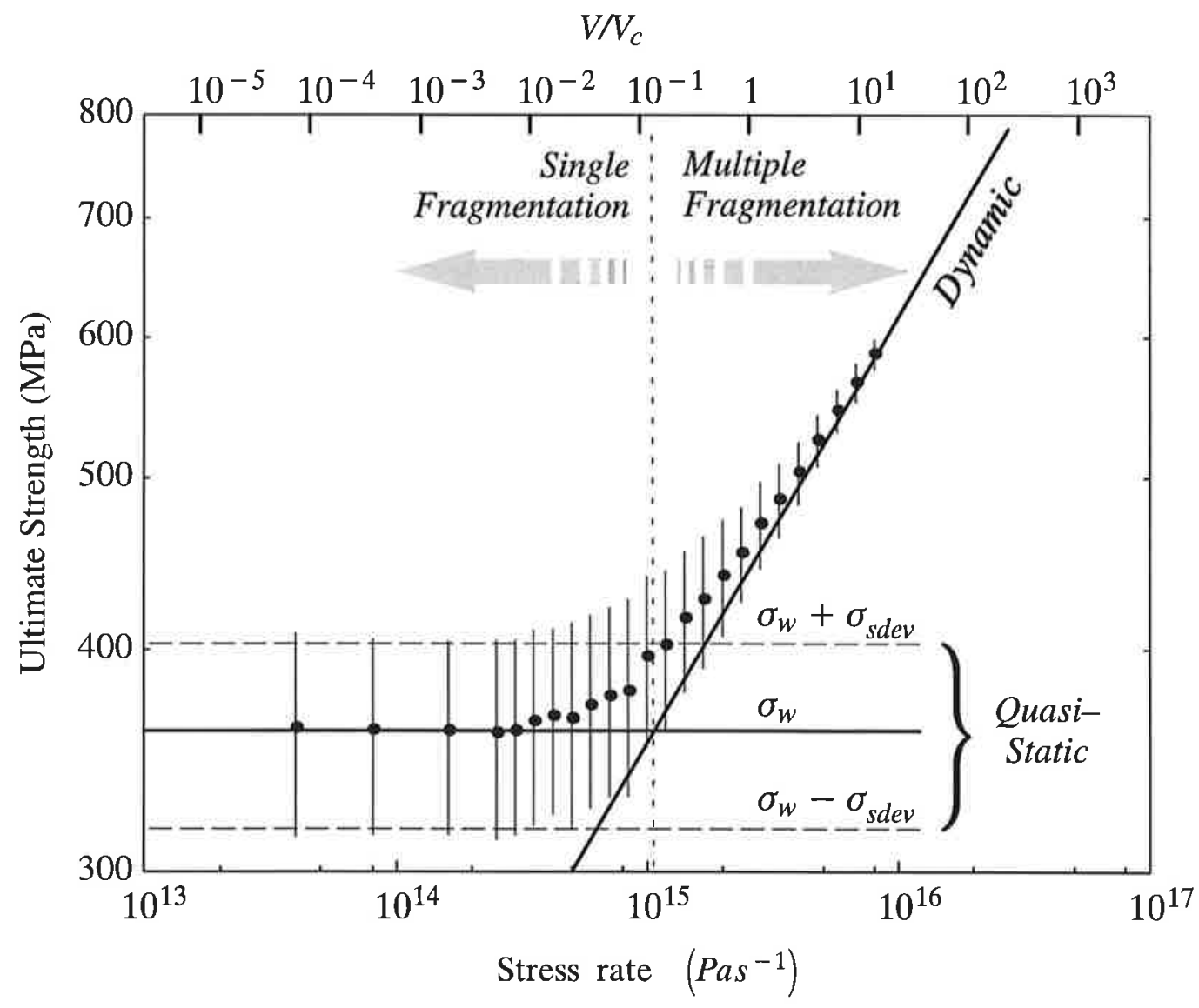

Figure 5: Ultimate strength vs. stress rate (SSiC). The dots and error bars represent results obtained by Monte-Carlo simulations (500 realizations/point) and their standard deviation (V=Veff).

error bars represent Monte-Carlo simulations (500 realizations per point). For a stress rate within $\left[0,5.10^{14} \mathrm{~Pa} \cdot \mathrm{s}^{-1}\right]$, the ultimate stress is not modified by the loading rate. When $\dot{\sigma}$ increases by approximately one order of magnitude, the ultimate strength follows the proposed solution (Eqn.(15)). During the single/multiple fragmentation transition, the difference between the solid lines (Eqns. (3) and (15)) and the 
Monte-Carlo simulations does not exceed $10 \%$. The standard deviation significantly decreases in the case of multiple fragmentation when the stress rate increases. Even if the ultimate strength has to be defined for both static and dynamic loadings by a mean value and a standard deviation, one can see that dynamic loadings lead to a more 'deterministic' behavior. For a SSiC ceramic, a stress rate up to $10^{13} \mathrm{~Pa} . \mathrm{s}^{-1}$ has shown no stress rate effect on the mean strength [11]. This observation is in good agreement with the result shown in Fig. 5.

The transition between single and multiple fragmentation can be estimated by

$$
\Sigma_{\mathrm{u}}(\dot{\sigma})=\sigma_{\mathrm{w}}
$$

The transition between quasi-static and dynamic descriptions defined by Eqn.(16) leads to the following inequalities

with

$$
\left\{\begin{array}{lll}
\dot{\sigma} V^{\frac{m+3}{3 m}}<f & \text { Single Fragmentation } \\
\dot{\sigma} V^{\frac{m+3}{3 m}} \geq f & \text { Multiple Fragmentation }
\end{array}\right.
$$

$$
f=\lambda_{o}{ }^{-1 / m} \sigma_{o} S^{1 / 3} a C\left[e \frac{6 m !}{(m+2) !} \Gamma\left(\frac{m+1}{m}\right)^{m+3}\right]^{1 / 3}
$$

It is worth mentioning that this transition does not only depend upon material parameters but also involves the volume $V$ of the considered structure. The response of a large structure can be considered as 'dynamic' for low stress rate even if the same material follows the weakest link hypothesis for the same loading applied on a smaller volume. There is therefore no relationship between material parameters and characteristic scales to describe the mechanical behavior. This transition can also be expressed by using the characteristic volume $V_{\mathrm{c}}(\dot{\sigma})$

$$
\begin{cases}\frac{V}{V_{\mathrm{c}}}<g(m) & \text { Single Fragmentation } \\ \frac{V}{V_{\mathrm{c}}} \geq g(m) & \text { Multiple Fragmentation }\end{cases}
$$

with

$$
g(m)=\left[e \frac{6 m !}{(m+2) !}\right]^{\frac{m}{m+3}} \Gamma\left(\frac{m+1}{m}\right)^{m}
$$

The volume $V_{\mathrm{c}}(\dot{\sigma})$ can therefore be considered as the characteristic scale for which a single/multiple fragmentation transition is observable. Furthermore, Fig. 5 shows that for $V / V_{\mathrm{c}} \geq 1$ the ultimate strength scatter is very small. This characteristic volume can be used in FE computations in which the mesh size has to be greater than or equal to $V_{\mathrm{c}}(\dot{\sigma})$ to use a continuum and deterministic description of damage.

\subsection{Application: Edge-On Impact}

As mentioned in Section 2.5, damage due to impact is localized in corridors when the impactor velocity is less than a critical value. The measured velocities for localization are listed in Table 2 and a significant difference between the two materials is obtained. The stress rates are calculated for each material for an impacted volume of $10 \times 100 \times 100 \mathrm{~mm}^{3}$. Contrary to the expected result, the two stress rates are comparable, with a difference less than $5 \%$.

Table 2. Impact velocities for the localization of damage and stress rates corresponding to the quasi-static/dynamic transition $\left(V=10 \times 100 \times 100 \mathrm{~mm}^{3}\right)$

\begin{tabular}{ccc} 
& $\mathrm{SSiC}$ & $\mathrm{SiC}-\mathrm{B}$ \\
\hline $\begin{array}{c}\text { Impact velocity } \\
(\text { localization })\end{array}$ & $\approx 40 \mathrm{~m} / \mathrm{s}$ & $\approx 185 \mathrm{~m} / \mathrm{s}$ \\
$\dot{\sigma}(V)$ & $2.4210^{13} \mathrm{~Pa} . \mathrm{s}^{-1}$ & $2.5210^{13} \mathrm{~Pa} . \mathrm{s}^{-1}$ \\
\hline
\end{tabular}


The localization cannot be related to the single/multiple failure transition. A more detailed observation of the experimental result of Fig. 4 shows that a corridor contains a high density of cracks, corresponding to a high (local) stress rate. Moreover, an analysis of the computed stress rate generated during an impact at $185 \mathrm{~m} / \mathrm{s}$ shows that the local stress rate at the corridor tips remains higher than the single/multiple transition stress rate. This leads to the conclusion that the localization in corridors is not a transient behavior between the dynamic and quasi-static behavior. Furthermore, it can be noticed that, due to the difference of strength between the two materials (Table 1), the maximum elastic energy reached before fragmentation for the SiC-B ceramic is greater than twice that of the SSiC ceramic. For low impact velocities, this energy may be insufficient for damage generation ( $\mathrm{SiC}-\mathrm{B}$ ). The energy contraction is then the only mechanism allowing a (localized) damage onset and leading to a maximum of energy dissipation.

\section{Conclusion}

A probabilistic approach has been proposed to describe the stress rate dependence of the fragmentation mechanism. A damage evolution law in tensile mode is derived for impacted ceramics. The material parameters (i.e., Weibull parameters) used in the model are obtained with quasi-static 3-point flexural tests. A closedform solution for the number of cracks nucleated is proposed and leads to the definition of the transition between single and multiple fragmentation. This transition is expressed by using characteristic quantities such as volume or time. It is found that the probabilistic nature of quasi-static failure progressively vanishes with higher stress rates. However, the localization of damage in corridors cannot be expressed in terms of transition between dynamic and quasi-static behavior.

\section{Acknowledgments}

The authors wish to thank E. Straßburger and H. Senf from the EMI for providing the pictures of Fig. 4. This work was funded by DSP/STTC.

\section{References}

[1] Orsini H. and Cottenot C. E., "Specific Test to Evaluate Intrinsic Ballistic Properties of Ceramic Materials Against an AP $12.7 \mathrm{~mm}$ Projectile. Application to Improve Ceramic Materials", (1995). In: Proc. 15 Int. Symp. on Ballistics, Jerusalem, (1995), pp. 183-190.

[2] Cagnoux J., "Déformation et ruine d'un verre pyrex soumis à un choc intense : étude expérimentale et modélisation du comportement", (1985). Thèse d'état, University of Poitiers.

[3] Weibull W., "A Statistical Theory of the Strength of Materials", (1939). Roy. Swed. Inst. Eng. Res. 151.

[4] Davies D.G.S., Proc. Brit. Ceram. Soc. 22, (1973), pp 429-452.

[5] Straßburger E., Senf H., Denoual C., Riou P. and Cottenot C. Proc. Fifth Interntional Conference on Mechanical and Physical Behaviour of Materials under Dynamic Loading. J. Phys. IV, 7, (Les Editions de Physique, Les Ulis, 1997), pp. C3 909-914.

[6] Serra J., "Image Analysis and Mathematical Morphology", (1982). Academic Press, London (UK).

[7] Jeulin D., "Anisotropic Rough Surface Modeling by Random Morphological Functions", (1985). In Proc. $4^{\text {th }}$ Symp. on Stereology, Göteborg (Sweden) and Acta Stereol., (1987), 6, pp. 183-189.

[8] Denoual C., Barbier G. and Hild F. "A Probabilistic Approach for Fragmentation of Brittle Solids under Dynamic Loading”, (1997). C. R. Acad. Sci., Paris, t. 325, Série IIb, pp. 685-691.

[9] Hild F. and Denoual C., "Probabilistic Model for the Dynamic Fragmentation of Brittle Solids", (1997). Proc. APS Conference on Shock Compression of Condensed Matter, Amherst (MA), USA (in press).

[10]PamShock, Users' Manual, ESI, (1997).

[11] Denoual C. and Riou P., "Comportement à l'impact de céramiques techniques pour blindages légers", (1995). ETCA Report 95 R 005. 